CPAP usage data were downloaded at the 2-4 week assessment, and at the 6 month assessment. Those who withdrew were assumed to have 0:00 $\mathrm{h} / \mathrm{n}$ usage.

Correlations were calculated between CPAP usage at the 6 month assessment and both the baseline characteristics and to the 2-4 week CPAP usage data.

\begin{tabular}{|c|c|c|}
\hline Variable & $\begin{array}{l}\text { Mean (SD), Median (IQR) or } \\
\text { Number (\%) }\end{array}$ & $\begin{array}{l}100 \% \\
\text { Range }\end{array}$ \\
\hline Age (mean; SD) & $57.9(7.2)$ & $45-75$ \\
\hline Gender (number male;\%) & $153(78.5 \%)$ & - \\
\hline Ethnicity (number white;\%) & $188(96.4 \%)$ & - \\
\hline BMI (mean kg/m²; SD) & $32.2(5.6)$ & $21.6-51.6$ \\
\hline \multicolumn{3}{|l|}{ Smoking status (number;\%) } \\
\hline Current & $17(8.7 \%)$ & - \\
\hline Ex-smoker & $102(52.3 \%)$ & - \\
\hline Never smoker & $76(39 \%)$ & - \\
\hline Reported snoring (number yes;\%) & $190(97.4 \%)$ & - \\
\hline Reported apnoeas (number yes;\%) & $142(72.8 \%)$ & - \\
\hline Reported choking (number yes;\%) & $66(33.8 \%)$ & - \\
\hline Reported nocturia (number yes;\%) & $114(58.5 \%)$ & - \\
\hline $\begin{array}{l}\text { Oxygen desaturation index (ODI, } \\
\text { median; IQR) }\end{array}$ & $10.2(4.7,17.5)$ & $0.5-58.0$ \\
\hline Epworth Sleepiness Score (ESS, mean; SD) & $7.9(4.4)$ & -18 \\
\hline $\begin{array}{l}\text { Short sleep apnoea quality of life index } \\
\text { (SAQLI, mean; SD) }\end{array}$ & $4.9(1.1)$ & $2.3-6.9$ \\
\hline SF-36 Physical Summary (mean; SD) & $42.0(12.3)$ & $9.4-61.3$ \\
\hline SF- 36 Mental Summary (mean; SD) & $48.1(10.3)$ & 19.9-63.7 \\
\hline
\end{tabular}

Results Median CPAP usage at 2-4 week follow-up was low at $2: 49 \mathrm{~h} / \mathrm{n}(\mathrm{n}=174$, IQR $0: 44,5: 13)$. Median usage at 6 month follow-up was $2: 17 \mathrm{~h} / \mathrm{n}(\mathrm{n}=195$, IQR 0:08, 4:54).

At 6 months males had significantly greater mean usage at $2: 56 \mathrm{~h} / \mathrm{n}$ compared to $1: 47 \mathrm{~h} / \mathrm{n}$ in females $(95 \%$ confidence intervals of the difference, $-1: 49$ to $-0: 09 \mathrm{~h} / \mathrm{n}, \mathrm{p}=0.02)$. There were no other significant predictors of 6 month usage (age, BMI, ODI, ESS, sleep symptoms, smoking status, ethnicity, SAQLI, SF-36).

Average usage of CPAP at 2-4 week assessment was moderately correlated with the average usage at the 6 month assessment $(\mathrm{r}=0.76, \mathrm{p}<0.001)$.

Conclusions Male gender predicted greater CPAP usage at 6 months, but no other baseline characteristics were predictive of CPAP usage in these minimally symptomatic patients with generally mild OSA. 2-4 week CPAP usage was predictive of 6 month usage, but by no means could all patients' usage be predicted at such an early stage. Thus in clinical practice, trials of CPAP are necessary in patients with minimally symptomatic OSA but it may be necessary for patients to try CPAP for longer than one month to determine those benefitting from treatment in the long term.

\section{S30 NUTRITION AND EXERCISE REHABILITATION IN OBESITY HYPOVENTILATION SYNDROME (NERO): A PILOT RANDOMISED CONTROLLED TRIAL}

${ }^{1} \mathrm{~S}$ Mandal, 'ES Suh, ${ }^{1} \mathrm{R}$ Harding, ${ }^{1} \mathrm{~A}$ Vaughan-France, ${ }^{1} \mathrm{M}$ Ramsay, ${ }^{1} \mathrm{~B}$ Connolly, ${ }^{1} \mathrm{D}$ Bear, ${ }^{2} \mathrm{H}$ McLaughlin, ${ }^{2} \mathrm{~S}$ Greenwood, ${ }^{3} \mathrm{M}$ Polkey, ${ }^{4} \mathrm{M}$ Elliott, ${ }^{5} \mathrm{~A}$ Douiri, ${ }^{2} \mathrm{~J}$ Moxham, ${ }^{1} \mathrm{~N}$ Hart. 'Lane-Fox Respiratory Unit, Guy's and St Thomas' NHS Trust, London, UK; ${ }^{2}$ King's College Hospital, London, UK; ${ }^{3}$ Royal Brompton and Harefield NHS Trust, London, UK; ${ }^{4}$ St James' Hospital, Leeds, Leeds, UK; ${ }^{5}$ Department of Primary Care and Public Health Sciences \& NIHR Biomedical Research Centre at Guy's and St Thomas' NHS Foundation Trust and King's College London, London, UK

\subsection{6/thoraxjnl-2015-207770.36}

Introduction We have previously shown that treatment of obesity hypoventilation syndrome (OHS) with non-invasive ventilation (NIV) results in weight reduction and an increase in physical activity (Murphy et al., 2012). We therefore hypothesised that a multi-modal rehabilitation programme, in addition to NIV, would lead to enhanced weight loss.

Method We conducted a randomised controlled trial of NIV alone vs. NIV and a personalised rehabilitation programme in patients with OHS. Subjects in the intervention group received a bespoke diet and exercise regime, from a dietician and physiotherapist. All patients, in both groups, were reviewed monthly for 3 months. Anthropometrics, exercise capacity and health related quality of life (HQRL) were measured at baseline and at 3 months. The primary outcome measure at 3 months was weight loss. Secondary outcomes included: body mass index (BMI), neck circumference (NC), waist circumference (WC), hip circumference $(\mathrm{HC})$ blood pressure $(\mathrm{BP})$, rectus femoris crosssectional area $\left(\mathrm{RF}_{\mathrm{CSA}}\right)$ and quadriceps maximal voluntary contraction (QMVC), 6 min walk distance (6MWD) and HRQL measures.

Results 37 subjects were randomised with data from 30 patients analysed at 3 months (15 in each group). There were no differences between the groups in all parameters measured at baseline. The intervention group showed greater weight loss than the control group $(-11.9 \pm 6.7$ vs. $-2.4 \pm 6.2 \mathrm{~kg} ; \mathrm{p}<0.0001)$. There were also differences in NC, WC and HC (all p $<0.001$, Table 1) with an improvement in BP observed in the intervention group (Table 1). In addition, there was an increase in weight corrected $\mathrm{RF}_{\mathrm{CSA}}$ and muscle strength $(\mathrm{p}<0.0001$, Table 1$)$ with an increase in $6 \mathrm{MWD}$ in the intervention group $(122 \pm 161$ vs. 46 $\pm 60 \mathrm{~m} ; \mathrm{p}=0.005$; Table1). Finally, HRQL improved in the intervention group as evidenced by a greater reduction in Epworth sleepiness score, an increase in severe respiratory insufficiency questionnaire sum score and a greater decrease in the hospital and anxiety depression score (Table 1 , all $\mathrm{p}<0.0001$ ).

Conclusion In patients with OHS, the addition of a hospitalhome hybrid personalised diet and exercise programme to standard NIV was shown to enhance weight loss as well as, skeletal muscle area and strength, exercise capacity and HRQL.

\section{REFERENCE}

1 Murphy PB, Davidson C, Hind MD, et al. Volume targeted versus pressure support non-invasive ventilation in patients with super obesity and chronic respiratory failure: a randomised controlled trial. Thorax. 2012;67:727-34

\title{
REFERENCES
}

1 Thorax 2010;65:829-32

2 Thorax 2012;67:1090-66 


\section{Spoken sessions}

Abstract S30 Table 1 Changes in anthropometrics, blood pressure, peripheral muscle area, peripheral muscle strength and exercise capacity

\begin{tabular}{|c|c|c|c|c|c|}
\hline & \multicolumn{2}{|c|}{ Control Group } & \multicolumn{2}{|c|}{ Intervention Group } & \multirow[b]{2}{*}{$\begin{array}{c}\text { p-value } \\
\text { ANCOVA }\end{array}$} \\
\hline & Baseline & 3 Month & Baseline & 3 Month & \\
\hline \multicolumn{6}{|c|}{ ANTHROPOMETERICS } \\
\hline Weight (kg) & $141.2 \pm 30.7$ & $138.8 \pm 34.6$ & $139.3 \pm 28.8$ & $127.4 \pm 25.3^{\#}$ & $<0.0001^{*}$ \\
\hline BMI $\left(\mathrm{kg} / \mathrm{m}^{2}\right)$ & $50.8 \pm 7.5$ & $50.3 \pm 8.5$ & $51.4 \pm 8.2$ & $47.4 \pm 8.3^{\#}$ & $<0.0001 *$ \\
\hline $\mathrm{NC}(\mathrm{cm})$ & $\begin{array}{c}44.0 \\
(42.0-48.0)\end{array}$ & $\begin{array}{c}44.0 \\
(41.0-47.5)\end{array}$ & $\begin{array}{c}48.0 \\
(38.0-49.4)\end{array}$ & $\begin{array}{c}43.2 \\
(41.0-46.0)\end{array}$ & $<0.0001^{*}$ \\
\hline WC (cm) & $\begin{array}{c}135.5 \\
(129.5-142.0)\end{array}$ & $\begin{array}{c}137.0 \\
(122.0-143.6)\end{array}$ & $\begin{array}{c}132.0 \\
(127.0-141.6)\end{array}$ & $\begin{array}{c}124.0^{\#} \\
(118.5-131.7)\end{array}$ & $<0.0001 *$ \\
\hline $\mathrm{HC}(\mathrm{cm})$ & $\begin{array}{c}151.5 \\
(145.3-162.3)\end{array}$ & $\begin{array}{c}151.0 \\
(137.9-160.1)\end{array}$ & $\begin{array}{c}149.0 \\
(134.9-163.7)\end{array}$ & $\begin{array}{c}142.0^{\#} \\
(130.5-159.5)\end{array}$ & $<0.0001 *$ \\
\hline \multicolumn{6}{|c|}{ CARDIOVASCULAR } \\
\hline $\begin{array}{l}\text { Systolic BP } \\
\text { (mmHg) }\end{array}$ & $\begin{array}{c}125 \\
(113-142)\end{array}$ & $\begin{array}{c}127 \\
(114-139)\end{array}$ & $\begin{array}{c}124 \\
(110-139)\end{array}$ & $\begin{array}{c}121 \\
(99-129)\end{array}$ & $0.002 *$ \\
\hline $\begin{array}{l}\text { Diastolic BP } \\
\text { (mmHg) }\end{array}$ & $\begin{array}{c}69 \\
(61-81) \\
\end{array}$ & $\begin{array}{c}78 \\
(71-81) \\
\end{array}$ & $\begin{array}{c}75 \\
(65-87) \\
\end{array}$ & $\begin{array}{c}69 \\
(63-77) \\
\end{array}$ & $0.005^{*}$ \\
\hline \multicolumn{6}{|c|}{ MUSCLE MASS, MUSCLE STRENGTH \& EXERCISE CAPACITY } \\
\hline $\begin{array}{l}\text { RF }_{\mathrm{CSA}} / \text { weight } \\
\text { (AU) }\end{array}$ & $\begin{array}{c}8.2 \\
(6.5-9.6)\end{array}$ & $\begin{array}{c}8.2 \\
(6.1-9.5)\end{array}$ & $\begin{array}{c}7.7 \\
(6.8-8.5)\end{array}$ & $\begin{array}{c}8.6^{\#} \\
(8.0-10.8)\end{array}$ & $<0.0001^{*}$ \\
\hline QMVC (kg) & $\begin{array}{c}24.5 \\
(16.5-34.3)\end{array}$ & $\begin{array}{c}25.5 \\
(18.8-35.4)\end{array}$ & $\begin{array}{c}26.5 \\
(16.7-29.4)\end{array}$ & $\begin{array}{c}28.1 \\
(17.3-31.2)\end{array}$ & $<0.0001^{*}$ \\
\hline 6MWD (m) & $\begin{array}{c}165 \\
(100-288) \\
\end{array}$ & $\begin{array}{c}275^{\#} \\
(123-343) \\
\end{array}$ & $\begin{array}{c}200 \\
(100-320) \\
\end{array}$ & $\begin{array}{c}340^{\#} \\
(300-370) \\
\end{array}$ & $0.005^{*}$ \\
\hline \multicolumn{6}{|c|}{$\begin{array}{l}\text { HEALTH RELATED QUALITY OF LIFE } \\
\end{array}$} \\
\hline ESS & $\begin{array}{c}12 \\
(8-16)\end{array}$ & $\begin{array}{c}10^{\#} \\
(5-15)\end{array}$ & $\begin{array}{c}11 \\
(7-14)\end{array}$ & $\begin{array}{c}6^{\#} \\
(2-10)\end{array}$ & $<0.0001 *$ \\
\hline SRI SS & $\begin{array}{c}54 \\
(38-69)\end{array}$ & $\begin{array}{c}49 \\
(42-70)\end{array}$ & $\begin{array}{c}65 \\
(50-67)\end{array}$ & $\begin{array}{c}70^{\#} \\
(57-79)\end{array}$ & $<0.0001^{*}$ \\
\hline HAD & $\begin{array}{c}13 \\
(10-23)\end{array}$ & $\begin{array}{c}12 \\
(9-18)\end{array}$ & $\begin{array}{c}12 \\
(7-18)\end{array}$ & $\begin{array}{c}8^{\#} \\
(3-15)\end{array}$ & $<0.0001 *$ \\
\hline
\end{tabular}

Abbreviations: $B M I=$ body mass index; $N C=$ neck circumference; $W C=$ waist circumference; $H C=h i p$ circumference; $B P=$ blood pressure; $6 M W D=$ six minute walk distance; $R F_{C S A}=$ rectus femoris cross sectional area; $Q M V C=$ quadriceps maximal voluntary contraction, ESS=Epworth sleepiness score; SRI SS= severe respiratory insufficiency questionnaire sum score; $H A D=$ Hospital anxiety and depression scale. Data are presented as mean $\pm S D$ or median (IQR).

\#denotes significant difference from baseline $p<0.05$, as determined by Wilcoxon Signed Rank test

* denotes significant difference between groups as determined by ANCOVA 


\section{Interventional progress}

\section{S31 SAFETY AND YIELD OF PHYSICIAN LED ULTRASOUND GUIDED TRANSTHORACIC LUNG/PLEURAL BIOPSIES}

R Reddy, M Naeem, G Tsaknis. Kettering General Hospital, Kettering, UK

\subsection{6/thoraxjnl-2015-207770.37}

Introduction Transthoracic ultrasound is important tool in assessing pleural effusions and guiding placement of chest drains. It also demonstrates pleural-based masses and lung tumours abutting the pleura. ${ }^{1}$ Such lesions are suitable for ultrasound guided full core needle biopsy. ${ }^{1}$ Percutaneous transthoracic lung biopsy with ultrasound guidance is not widely performed by respiratory physicians. $^{1}$

Objective To assess safety and yield of ultrasound guided transthoracic biopsy performed by respiratory physicians.

Methods The procedures were carried out in an outpatient or bed side setting between April 2014 and Jun 2015. Apart from checking clotting and omitting antiplatelet/anticoagulants no special prior preparations were undertaken. Under real time transthoracic ultrasound, lesions involving pleura or abutting the pleura which were $>1.5 \mathrm{~cm}$ were sampled 2-3 times with a full core biopsy needle (Biopince 18G). Repeat thoracic ultrasound was done after 10 min to check for pneumothorax. Patients were discharged home around $30 \mathrm{~min}$ post procedure.

Results 51 patients underwent full core biopsy for suspected peripheral lung (44), pleural based (6) and Mediastinal tumours (1). The biopsies were considered adequate in 47 cases (94\%). Diagnosis was achieved in 43 patients with an overall yield of $84 \%$ (Table 1) whilst the yield for malignancy was $82 \%(36 / 44)$. Of the 8 patients with a negative biopsy, malignancy was diagnosed at surgery in 2 patients and CTGB (CT guided biopsy) in 6 patients. Complications were minimal with one patient developing a small pneumothorax (2\%) and another had a small subcutaneous hematoma. After the introduction of the service the waiting list for CT guided biopsies in our hospital has been eliminated.

\begin{tabular}{llll}
\multicolumn{2}{l}{ Abstract S31 Table 1} \\
\hline & Malignant & Benign & Nondiagnostic \\
\hline Total & $36(70 \%)$ & $7(14 \%)$ & $8(16 \%)$ \\
$(n=51)$ & & (Vasculitis 1, TB 1, & (All proven malignant \\
& & Non specific inflammation 3, other 2) & later) \\
\hline
\end{tabular}

Conclusion Ultrasound guided peripheral lung/pleural mass biopsy can be performed by trained respiratory physicians with excellent yield and very low complication rate. Used appropriately it reduces the waiting list for CTGB.

\section{REFERENCE}

1 Diacon AH, Schuurmans MM, Theron J, et al. Safety and yield of ultrasoundassisted transthoracic biopsy performed by pulmonologists. Respiration 2004;71 (5):519-22 S32 VIRTUAL BRONCHOSCOPIC NAVIGATION FOLLOWED BY
RADIAL EBUS TO BIOPSY PERIPHERAL PULMONARY LESIONS: A PILOT STUDY

N Denny, J Mills, L Brown, SJ Fowler, M Munavvar. Department of Respiratory Medicine, Lancashire Teaching Hospitals NHS Foundation Trust, Preston, UK

\subsection{6/thoraxjnl-2015-207770.38}

Introduction Detection of peripheral pulmonary lesions (PPLs) is on the rise but an accurate means of obtaining a tissue diagnosis without high risk of complications is lacking. ${ }^{1}$ Virtual bronchoscopic navigation (VBN) guides the bronchoscope under direct vision and, in combination with radial endobronchial ultrasound (R-EBUS) or ultrathin bronchoscopy, may enhance the diagnostic yield of PPLs with a minimal complication rate. ${ }^{2}$

Aims To pilot the use of VBN in the diagnosis of PPLs. To identify patient and lesion characteristics that predict successful VBN. Methods Images from chest CT (slice width 1-1.25 mm) were acquired from patients, and lesion features, including location and presence of a bronchus sign (bronchus contained within PPL), were recorded. CT images were transferred to a portable workstation and Lungpoint Broncus (C) was used to create a virtual pathway to the PPL. Bronchoscopy was performed with VBN followed by REBUS guidance, under conscious sedation, and biopsies obtained. Pre-procedure characteristics, biopsy adequacy, biopsy outcome, 30-day follow up and complications were recorded.

Results The median age of our cohort $(\mathrm{n}=7)$ was 79 and all patients had one or more comorbidities. PPL median size was 28 $\mathrm{mm}$ and all were located in sub-segmental bronchi. VBN guided the operator to the correct site in six cases. Adequate biopsies were taken from five patients; four had a positive bronchus sign. Three adequate biopsies received a diagnosis of primary lung cancer; those remaining were negative. One patient with inadequate biopsies underwent transthoracic needle biopsy (TTNB) and was diagnosed with primary lung cancer. No complications occurred in spite of the significant co-morbidity of this patient cohort.

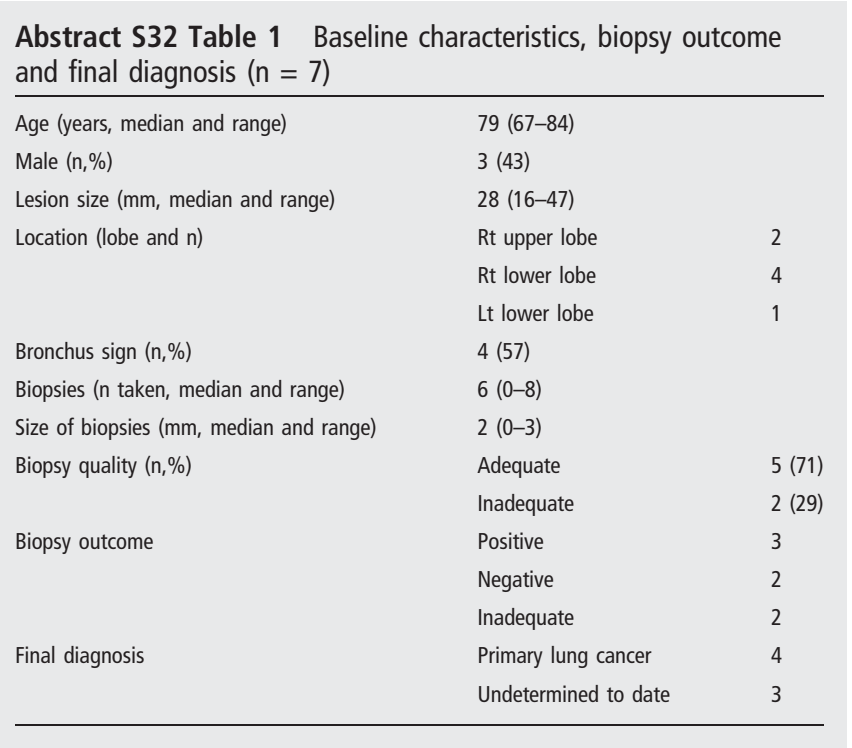

Discussion Our preliminary data suggest that in a selected patient cohort with a bronchus sign, VBN may be a useful and safe adjunct to R-EBUS to obtain a tissue diagnosis from PPLs. In contrast, TTNB has a high diagnostic sensitivity but is 